\title{
Evaluation of Thermo-Mechanical Properties of Carbon/Epoxy Amino-Functionalized Graphene Nanoplatelet Composite
}

\author{
Mohammad K Hossain ${ }^{1 *}$, Md Mahmudur R Chowdhury ${ }^{1}$ and Nydeia W Bolden ${ }^{2}$ \\ ${ }^{1}$ Department of Mechanical Engineering, Tuskegee University, USA
}

${ }^{2}$ Air Force Research Laboratory Munitions Directorate, USA

*Corresponding author: Mohammad K Hossain, Associate Professor of Mechanical Engineering, Tuskegee University, Tuskegee, AL 36088, USA.

Received Date: February 11, 2020

Published Date: February 19, 2020

\begin{abstract}
A systematic study has been conducted on processing and characterizing of carbon fiber reinforced epoxy polymer (CFRP) composites to enhance its viscoelastic and thermal properties through the integration of optimized amount of amino-functionalized $\left(\mathrm{NH}_{2}-\mathrm{GNP}\right)$ graphene nanoplatelet (GNP). Epoxy resin, EPON 828, was modified infusing $0.1,0.2,0.3,0.4$, and $0.5 \mathrm{wt} \% \mathrm{of} \mathrm{NH}_{2}-\mathrm{GNP}$ as a nano reinforcing agent. The GNP was infused into EPON 828 resin using a high intensity ultrasonic processor followed by a three-roll milling for better dispersion. Epikure 3223 curing agent was then added to the modified resin and mixed using a high-speed mechanical stirrer. The nanophase epoxy was then used to fabricate CFRP nanocomposites using the compression molding process. Dynamic mechanical analysis (DMA) and thermomechanical analysis (TMA) were performed to analyze the viscoelastic and thermal performances of these composites. In all cases, the $0.4 \mathrm{wt} \%$ GNP-infused epoxy nanocomposite exhibited the best properties. The $0.4 \mathrm{wt} \%$ GNP modified carbon fiber/epoxy composite demonstrated $19 \%$ and $23 \%$ improvement in storage modulus and loss modulus, respectively. Moreover, there were about $13 \%$ and $28 \%$ reduction in the coefficient of thermal expansion before and after glass transition temperature, respectively. Glass transition temperature and crosslink-density were also observed to be enhanced for the $0.4 \mathrm{wt} \%$ loading due to better interfacial interaction and effective load transfer between the $\mathrm{NH}_{2}$-GNP and the epoxy resin.
\end{abstract}

Keywords: Graphene nanoplatelet; Viscoelastic properties; Amino functionalized; DMA; TMA

\section{Introduction}

Demand for fiber reinforced polymer (FRP) composites in aviation, automotive, naval, structural, and recreational sporting industries is increasing because of their excellent corrosion resistance, lightweight, higher specific strength and stiffness to weight ratio, ease of reparability, ability to absorb noise and damp vibrations, design flexibility, and ease of manufacturing processes [1-2]. Researchers both in academia and industry are trying to develop multifunctional materials that demonstrate optimized mechanical, thermal, and electrical properties to use the same bulk material for multipurpose uses. Improvement in transverse properties of FRP composites such as enhanced fiber/ matrix interfacial strength as well as improved matrix toughness would reduce the chance of out-of-plane damage and enhance the overall performance of FRP composites. In the last two decades, researchers have successfully enhanced the matrix properties by incorporating various nanoparticles including nanoclay, carbon nanofiber (CNF), carbon nanotube (CNT), and silicon carbide. The integration of nanoparticles into the epoxy resin and its fiberreinforced composites improves out of plane properties. Among all nanoparticles, CNT has been proven to be a potential candidate for matrix modification because of its exceptional strength and stiffness, high specific surface area, and high aspect ratio [3-5]. However, due to the higher production cost of CNT [6], the mass production of CNT-based multifunctional composite materials is also expensive. On the other hand, the graphene nanoplatelet (GNP) having a two dimensional structure is composed of several layers of graphite nanocrystals stacked together [7-8]. The GNP has been providing better reinforcement and conducting fillers along 
with greatly improved mechanical and thermal properties due to their planar structure and higher aspect ratio. It is considered to be the thinnest material in the universe with immense application potential [9-10]. It is also expected to be the next potential candidate as a nanofiller to produce cost-effective composite materials. Compared with other classic 2D nanofillers such as nanoclay, the GNP has lower mass density and is highly electrically and thermally conductive due to the sp2 hybridized carbons in the monolayer graphene within the GNP. The GNP also possesses superior mechanical properties with a reported modulus of 1100 GPa and strength of $125 \mathrm{GPa}$ [11]. Therefore, the GNP is truly an ideal candidate for improving the properties of polymers as well as their FRP composites for multipurpose practical applications. Generally, the GNP is prepared by intercalating graphite either with metal ions or by acid treatment. This is further exfoliated by thermal treatment to yield GNP [12-13]. This 2D layered structure also possesses excellent electrical and thermal conductivity along with its high modulus. However, these properties strongly depend on the number of layers stacked in the GNP, the degree of crystallinity in the graphitic plane, their aspect ratio, and the order of stacking [1415]. Perhaps the most interesting application for this material is to use it as a filler in composite structures. They have already shown promising results in the field of polymer composites as sensor, thermal interface materials, and to create electrically conducting polymers [16-17].

There is a growing demand for low cost materials in the industry. With this rationale, there is extensive research in progress on polymer-based nanocomposites for a wide range of properties such as electrical, thermal, mechanical, and magnetic. The graphene nanoplatelet (GNP) is the novel nanofiller due to its exceptional functionalities, high mechanical strength, chemical stability, abundance in nature, and cost-effectiveness. Moreover, it possesses an extremely high-specific surface area which carries a high level of transferring stress across the interface and provides higher reinforcement effect compared to the CNT. Superior properties of graphene in comparison with those of polymers are also elucidated in polymer/graphene nanocomposites. They showed superior mechanical, thermal, gas barrier, electrical, and flame resistance properties [18-21]. Compared to the mechanical and electrical properties of nanoclay or other carbon-filler based polymer nanocomposites, graphene-based polymer nanocomposites possess better mechanical and electrical properties [18, 20-21]. The Graphene behaves as a better nanofiller than the CNT [2224]. The positive change in the nanocomposites' physiochemical properties depends on the distribution of the graphene layer in the polymer matrix. It also depends on the interface bonding between them. Graphene reinforced polymer composite's final properties are governed by the interface bonding between the graphene and the host polymer.

Dynamic mechanical thermal analysis (DMTA) was performed to observe laminates' stiffness behavior as a function of temperature and study the effect of GNP on viscoelastic properties of the carbon fiber reinforced epoxy polymer (CFRP) composite. In general, storage modulus, loss modulus, and glass transition temperature of laminates in the glassy regions and vicinity of the glass transition temperature should be increased upon loading of the GNP. This behavior can be attributed to the improved dispersion and interaction between the GNP and the epoxy due to the formation of covalent bonds between them. Better dispersed GNP must dissipate energy due to resistance against viscoelastic deformation of the surrounding matrix.

Fracture toughness and thermal conductivity were improved by $43 \%$ and $14 \%$, respectively, for $1 \mathrm{wt} \%$ and $2 \mathrm{wt} \%$ GNP-loaded epoxy nanocomposites compared to those in the neat system [25]. An increase in dynamic mechanical properties up to $0.5 \mathrm{wt} \%$ loading of GNP with the improvement of about $16 \%$ in storage modulus compared to the reference one was also reported. However, the glass transition temperature $\left(\mathrm{T}_{\mathrm{g}}\right)$ did not exhibit any significant improvement. The effect of the graphene on the linear coefficient of thermal expansion (CTE) is demonstrated by an improvement in the thermal expansion study where temperature was set below the glass transition temperature. The neat epoxy resin exhibited a CTE of approximately $8.2 \times 10^{-5}{ }^{\circ} \mathrm{C}^{-1}$, whereas $5 \mathrm{wt} \%$ graphitefilled epoxy composites exhibited a $31.7 \%$ reduction in the CTE value below $\mathrm{T}_{\mathrm{g}}$. Epoxy/graphene composites were prepared using an insitu process and their electromagnetic interference (EMI) shielding studies were also examined [26]. Using $25 \mathrm{wt} \%$ loading of commercially available GNP, a $18 \%$ enhancement in thermal conductivity was observed with the GNP/Silicone composite prepared by the three-roll milling technique [27]. Another study showed that due to a poor dispersion of the filler like neat graphite, expanded graphite, and graphene nanoplatelet in an epoxy matrix, increased the thermal conductivity slightly for the integration of GNP and decreased if the filler content is increased beyond 0.6 vol\% [28-29]. Study of non-covalent functionalization of graphene sheets dispersed in epoxy recorded an $800 \%$ increment in the thermal conductivity using the $4 \mathrm{wt} \%$ filler loading. This is mainly because of the strong interaction between the matrix and the filler. This helps in reducing the interface thermal resistance and also the homogenous dispersion that happens due to the functionalization [30].

The surface modification of nanofillers helps rejuvenate the interaction between the matrix and the nanofiller ensuing a better dispersion quality and high performance. Better viscoelastic properties and enhanced interface between the two components of the polymer matrix can be obtained by applying modification through chemical bonding [31-33]. Amino-functionalized carbon nanotube (CNT) has been extensively used to improve the interfacial interaction with epoxy matrices [34-36]. In analogy to the CNT, covalent bond formation between the epoxy resin and the amine group present on the amino-functionalized GNP surface is anticipated [37-38]. The functionalization performs two simultaneous actions to facilitate the interfacial bonding with the matrix and accommodating graphenic sheets at the molecular level 
which are highly desirable. Direct impact of well dispersed graphene and improved interfacial bonding on the mechanical properties is studied and compared with theoretical predictions [39].

There have been a number of studies on mechanical, electrical, and thermal properties of exfoliated graphene/graphene oxide/ GNP reinforced polymeric composites. However, there is no study reported in the open literature on the effect of amino-functionalized GNP on viscoelastic and thermal properties of FRP composites. The wide range of attractive properties and increasing use of these nanophased composites in important areas of industries and the insufficient data in the relevant field have led the authors to select this research project. In this study, amino-functionalized GNP reinforced carbon fiber/epoxy nanocomposites were manufactured using a combination of sonication and 3 roll mixing process. DMA and TMA were performed to investigate the effect of GNP on viscoelastic and thermomechanical properties of carbon fiber/ epoxy composites. Resultant outcomes containing different $\mathrm{wt} \%$ of GNP loading were then compared with those of the conventional carbon fiber/epoxy composite.

\section{Materials and Methods}

\section{Materials}

The matrix used in this study is a two part system manufactured by Miller Stephenson Chemical Company, Danbury: Part A is EPON 828 (Diglycidyl Ether of Bisphenol A (DGEBA), which is a low viscosity liquid epoxy resin manufactured using difunctional Bisphenol A and epichlorohydrin, and Part B is Epikure 3223, a Diethylenetriamine (DETA) used as a curing agent of epoxy resin. Carbon fabric of 8-harness satin weave purchased from US composites was used as reinforcement to fabricate laminates using the compression hot press technique. The GNP functionalized with amine groups $\left(-\mathrm{NH}_{2}\right)$ was received from Cheap Tubes Inc, Vermont, USA. The GNP consists of small stacks of graphene. The GNP had an average thickness less than $5 \mathrm{~nm}$ and specific surface area about $700 \mathrm{~m}^{2} / \mathrm{g}$. The GNP was covalently functionalized by amine $\left(-\mathrm{NH}_{2}\right)$ in order to achieve the required exfoliation and dispersion. The concentration of functional groups was less than $7 \%$.

\section{Manufacturing process}

First, pre-determined amount of GNP (0.1-0.5 wt\%) was mechanically mixed with epoxy resin Part-A by a mechanical stirrer for 4-5 minutes. The mixture was then put into a sonicator for 1 hour at $35 \%$ amplitude and 40 s on/ 20 s off cycle pulse mode. To avoid premature polymerization, this mixture was placed in a cooling bath. The sonicated mixture was then passed through three rollers to further improve the dispersion of GNP. In this process, GNPs were further de-agglomerated and uniformly dispersed in resin by the induction of a high shear force in the mixture. The gap space was incrementally reduced from 20 to $5 \mu \mathrm{m}$ between the rolls and multiple passes were used. The speed ratio of the three rollers was 1:3:9 with a maximum speed of $140 \mathrm{rpm}$. The Epoxy-GNP mixture was then mixed with the curing agent Epikure 3223 according to the stoichiometric ratio (Part A: Part B = 12:1). The mixture was then placed in a vacuum oven at $40{ }^{\circ} \mathrm{C}$ for 10 minutes to ensure the complete removal of entrapped bubbles and thus reduce the chance of void formation. Nanophased carbon fiber reinforced polymer (CFRP) composites were fabricated by employing a combination of hand lay-up and compression hot press techniques. Carbon woven fabrics were stacked into eleven layers maintaining their parallel orientation. Modified epoxy resin was smeared uniformly on each fabric layer using a brush and a wooden roller. The stack was then wrapped with a bleeder cloth and a nonporous Teflon cloth. Finally, the stack was placed on the platen of the hot press where pressure and temperature were controlled precisely to make sure maximum wetting of fabrics with matrix and compaction of the layup as well as curing. Temperature was kept at $60^{\circ} \mathrm{C}$ for 1 hour to attain enough flow of resin at a lower viscosity as compared to the room temperature and at the same time not to let it flow out of the layup. Temperature was then ramped to $100{ }^{\circ} \mathrm{C}$ and maintained for 1 hour to obtain the completely cured carbon- epoxy composite. Similarly, the conventional carbon/epoxy was manufactured using the compression molding process. Samples were cut and prepared from various portion of the panels for DMA and TMA tests according to ASTM standards to investigate the effect of amino-functionalized GNP on viscoelastic and thermal properties of these composites.

\section{Material characterization}

Dynamic mechanical analysis (DMA): DMA was performed with a TA Instruments dynamic mechanical analyzer (Model Q800) according to the ASTM D4065-01 standard under a dual cantilever beam mode with a frequency of $1 \mathrm{~Hz}$ and an amplitude of $15 \mu \mathrm{m}$. The temperature was ramped from $30{ }^{\circ} \mathrm{C}$ to $200{ }^{\circ} \mathrm{C}$ at a rate of 10 ${ }^{\circ} \mathrm{C} / \mathrm{min}$. A minimum of five samples of each category were tested.

Thermo mechanical analysis (TMA): TMA tests were carried out on a TA instruments thermo mechanical analyzer (Model Q400) operating in an expansion mode at a heating rate of $10^{\circ} \mathrm{C} / \mathrm{min}$ from $30{ }^{\circ} \mathrm{C}$ to $200^{\circ} \mathrm{C}$. A minimum of five samples of each type were tested, and the CTE for each of those samples was determined before the glass transition temperature.

\section{Results and Discussion}

\section{Dynamic mechanical analysis (DMA)}

Various temperature dependent properties of laminated composites such as storage modulus, loss modulus, and tan $\delta$ were obtained by performing dynamic mechanical analysis test. These properties characterize stored elastic energy and the energy dissipated during mechanical straining both of which are highly affected by fillers characteristics i.e. geometry, weight fractions, dispersion state of fillers in matrix as well as adhesion between the reinforcement and the matrix. Figure 1 shows the temperature dependence of storage modulus where temperature is in the range of $30-200{ }^{\circ} \mathrm{C}$. For different laminates, storage modulus at $30^{\circ} \mathrm{C}$ has been presented in Table 1 and the addition of GNP has resulted in significant improvement. The storage modulus was improved 
up to $19 \%$ with the addition of the $0.4 \mathrm{wt} \%$ of GNP at $30{ }^{\circ} \mathrm{C}$. This improvement is due to possible enhanced interaction between the well dispersed nanofiller and matrix. More sites for GNP/polymer interaction might have been provided by a better dispersion of the GNP at the $0.4 \mathrm{wt} \%$, whereas, the formation of a strong covalent bond shown in Figure 2 is due to the presence of amino-functional groups of GNP and its reaction with the epoxy. Hydrogen atoms in amine groups of DETA molecule (hardener) form self-crosslink with each other through reaction with the epoxide group of DGEBA resin molecules in case of control epoxy samples. In case of nanophased samples (Figure 2), at first the interfacial reaction between amine functional groups of GNP and epoxide groups of DGEBA resin takes place by ring opening reaction while EPON 828 (Part A) and GNP$\mathrm{NH}_{2}$ are mixed together. This modified Part-A establishes a strong covalent bond between the epoxy and the GNP upon further mixing with Part-B of epoxy resin and thereby crosslinking sites and interfacial bonding are boosted.

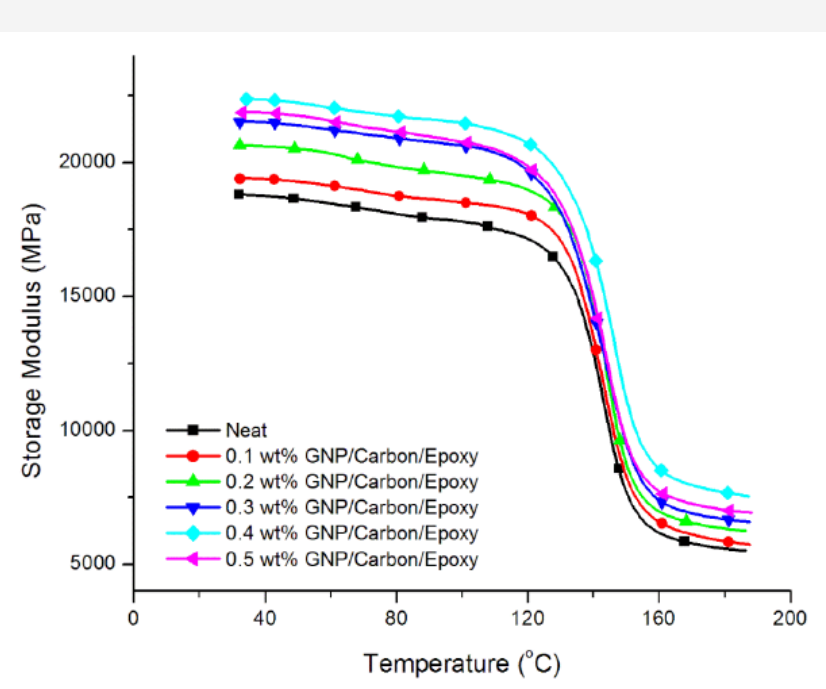

Figure 1: Storage modulus of GNP reinforced and control fiber reinforced composites.

(a) Reaction of epoxide group (DGEBA) with primary amine of functionalized GNP

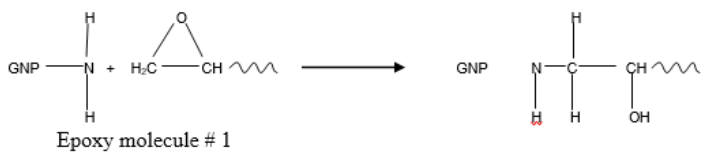

(b) Reaction of epoxide group (DGEBA) with primary amine of functionalized GNP

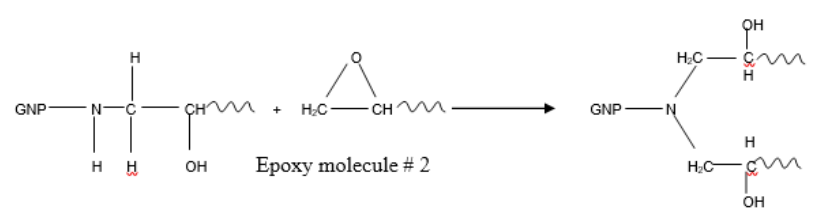

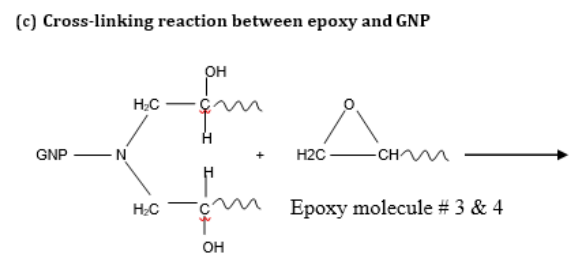

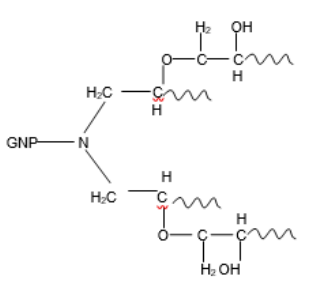

Figure 2: Schematic representation of interfacial reaction between DGEBA and GNP-NH2.

The epoxy chain molecular motion around GNP might have been abridged by the formation of covalent bond and the enhanced interaction. This abridgement may have resulted in a significant change of elastic and viscous properties in nanocomposites. However, at the $0.5 \mathrm{wt} \%$ loading, the observed decrease in storage modulus can be attributed to an increase of agglomeration of the
GNP and this increase of agglomeration reduces the crosslinking sites. Therefore, the storage modulus decreases as a result of possible increased molecular motion and movement of chain. The covalent bond between the epoxy and the GNP is the obvious factor in the improvement of thermo-mechanical properties. 
Table 1: DMA results of control and GNP reinforced carbon fiber/epoxy composites.

\begin{tabular}{|c|c|c|c|c|c|c|c|c|}
\hline \multicolumn{9}{|c|}{ Viscoelastic Properties of GNP/Carbon/Epoxy Nanocomposites } \\
\hline $\begin{array}{l}\text { Specimen } \\
\text { Category }\end{array}$ & $\begin{array}{l}\text { Storage Modu- } \\
\text { lus (MPa) }\end{array}$ & $\begin{array}{c}\text { \% Change } \\
\text { W.R.T Control }\end{array}$ & $\begin{array}{c}\text { Loss } \\
\text { Modulus } \\
\text { (MPa) }\end{array}$ & $\begin{array}{c}\% \\
\text { Change } \\
\text { W.R.T } \\
\text { Control }\end{array}$ & $\begin{array}{c}\text { Glass Transition } \\
\text { Temperature } \\
\left({ }^{\circ} \mathrm{C}\right)\end{array}$ & $\begin{array}{c}\text { \% Change } \\
\text { W.R.T Control }\end{array}$ & $\begin{array}{l}\text { Average Stor- } \\
\text { age Modulus } \\
@ 180^{\circ} \mathrm{C}\end{array}$ & $\begin{array}{l}\text { Apparent Cross- } \\
\text { link Density } \\
\left(\mathrm{mol} / \mathrm{cm}^{3}\right)\end{array}$ \\
\hline Control & $18818 \pm 849$ & - & $1307 \pm 56$ & - & $139.46 \pm 1.43$ & - & $5582 \pm 121$ & $1.48 \pm 0.03$ \\
\hline $0.1 \mathrm{wt} \%$ & $19409 \pm 992$ & 3.14 & $1420 \pm 41$ & 8.64 & $143.7 \pm 1.38$ & 3.04 & $5867 \pm 287$ & $1.56 \pm 0.02$ \\
\hline $0.2 \mathrm{wt} \%$ & $20648 \pm 772$ & 9.72 & $1471 \pm 59$ & 12.54 & $147.31 \pm 1.84$ & 5.62 & $6363 \pm 268$ & $1.69 \pm 0.04$ \\
\hline $0.3 \mathrm{wt} \%$ & $21523 \pm 1066$ & 14.37 & $1537 \pm 62$ & 17.59 & $150.4 \pm 2.21$ & 8.02 & $6687 \pm 314$ & $1.77 \pm 0.03$ \\
\hline $0.4 \mathrm{wt} \%$ & $22390 \pm 964$ & 18.98 & $1610 \pm 81$ & 23.18 & $155.96 \pm 1.64$ & 11.83 & $7684 \pm 252$ & $2.04 \pm 0.02$ \\
\hline $0.5 \mathrm{wt} \%$ & $21880 \pm 1158$ & 16.27 & $1517 \pm 77$ & 16.07 & $147.94 \pm 2.61$ & 6.08 & $7036 \pm 219$ & $1.87 \pm 0.04$ \\
\hline
\end{tabular}

Loss modulus of control and nanophased carbon fiber/ epoxy composites is presented in Figure 3. Loss modulus for nanoparticles reinforced carbon fiber/epoxy composites is much higher than the control one. The CFRP composite reinforced with the $0.4 \mathrm{wt} \%$ GNP demonstrated the highest loss modulus; thus, the highest amount of energy is dissipated while three-point bending load is applied. When the load is applied, nanoparticles try to hold the laminates in place; thereby more amount of energy is required to deform the sample. Thus, nanoparticles reinforced composites required a higher load and loss modulus increased for nanophased composites.

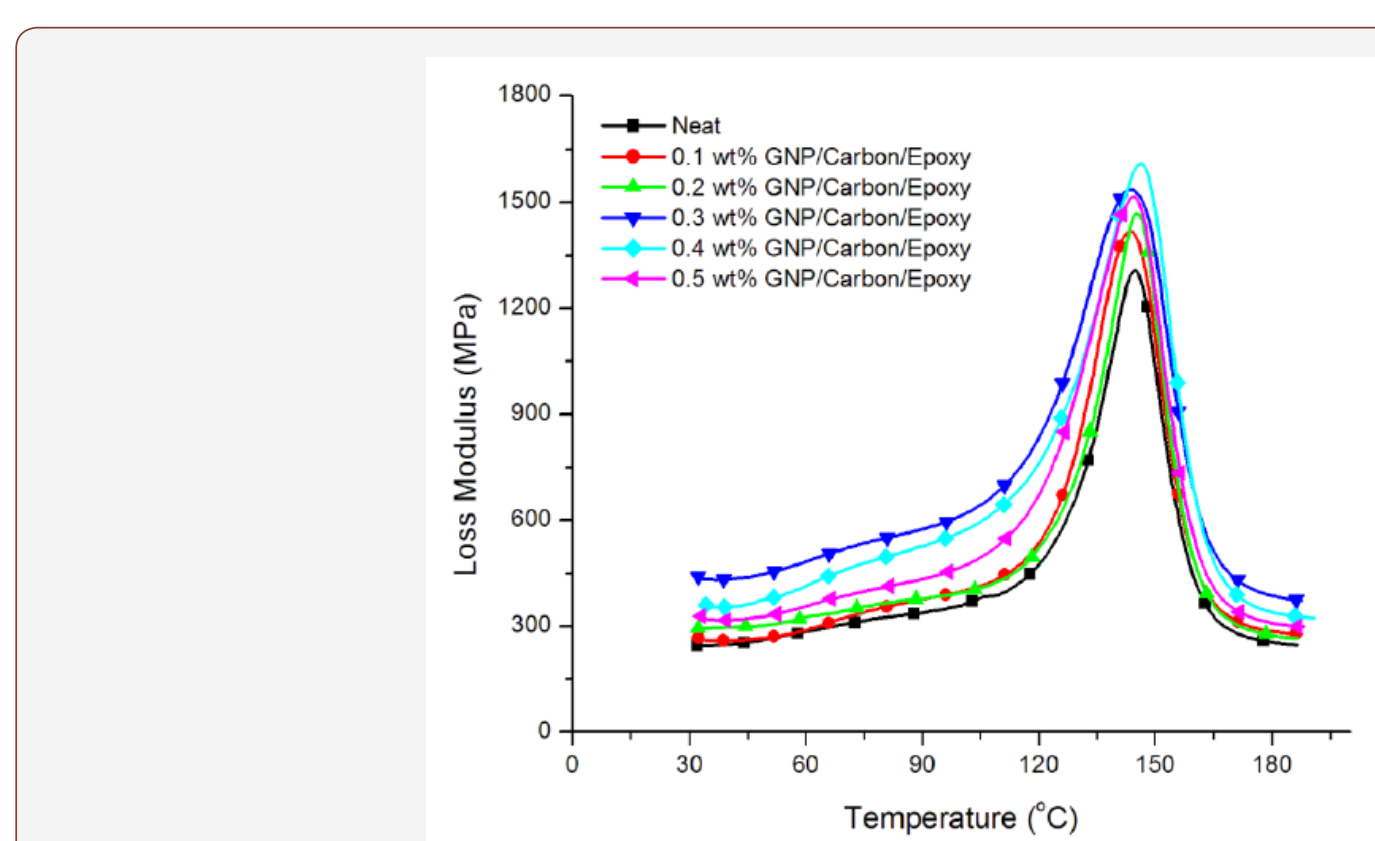

Figure 3: Loss modulus of control and GNP reinforced carbon fiber/epoxy composites.

The storage modulus drops sharply above $120{ }^{\circ} \mathrm{C}$ because of the easier movement of the polymer chain. This temperature region with such a behavior is roughly termed as glass transition temperature $\left(\mathrm{T}_{\mathrm{g}}\right)$. A substantial improvement in the rubbery plateau modulus was observed for the carbon/GNP/epoxy composite. The average rubbery plateau modulus at $180{ }^{\circ} \mathrm{C}$ is measured as 5582 , $5867,6368,6687,7684$, and $7036 \mathrm{MPa}$ for control, 0.1, 0.2, 0.3, 0.4, and $0.5 \mathrm{wt} \%$ GNP- infused composites, respectively. The operating region lies before the $\mathrm{T}_{\mathrm{g}}$ and the region beyond the $\mathrm{T}_{\mathrm{g}}$ is termed as the rubbery plateau. Reinforcing effect by the GNP, limited mobility from enhanced polymer-nanofiller interaction and augmented crosslink density are the factors which affect this enhancement of the rubbery plateau modulus because it improves the composite performance at a higher temperature. This increase in rubbery plateau modulus indicates an enhancement of the $\mathrm{T}_{\mathrm{g}}$ through increased crosslink density of the polymer [40]. Calculation of crosslink density was carried out using the DMTA test results. Crosslink density of epoxy composites can be calculated by using the following relation according to the theory of rubber elasticity:

$$
\lambda=\frac{G}{R T}
$$


Where $\lambda$ is the crosslink density expressed in moles of elastically effective network chains per cubic centimeter of sample, $\mathrm{G}$ is the storage modulus in the rubbery region at a temperature well above $\mathrm{T}_{\mathrm{g}}, \mathrm{R}$ is the universal gas constant, and $\mathrm{T}$ is the absolute temperature at which experimental modulus was selected. The results show that the crosslink density increased with an increase of storage modulus in rubbery region. Figure 4 shows apparent crosslink density at different weight percentages of GNP loading. Crosslink density increased up to a loading of $0.4 \mathrm{wt} \%$ GNP and then decreased. Hence, maximum rubbery modulus in the $0.4 \mathrm{wt} \%$ GNP reinforced composite has maximum crosslink density; thus, it maximizes the $\mathrm{T}_{\mathrm{g}}$. The decrease in crosslink density at $0.5 \mathrm{wt} \%$ is again can be attributed to a poor GNP dispersion that has reduced the crosslinking sites.

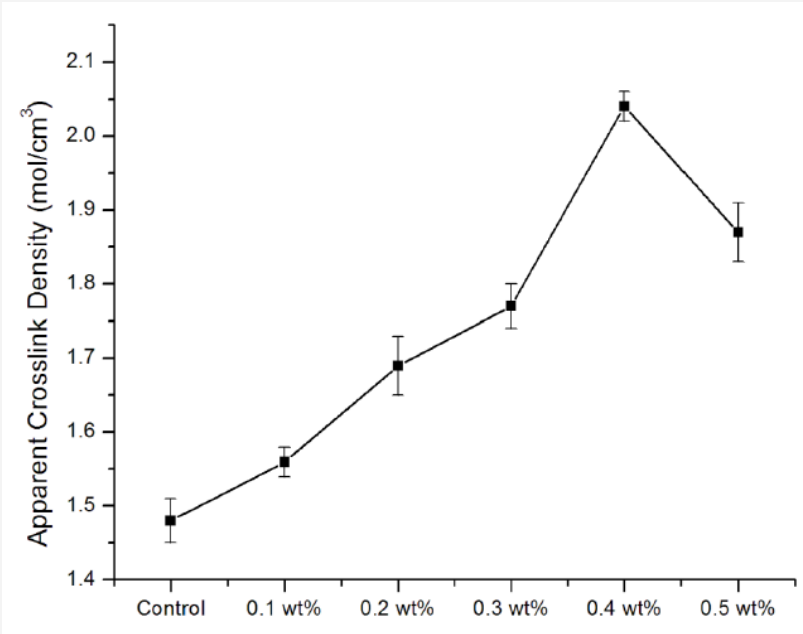

Figure 4: Effect of amino-functionalized GNP content on crosslink density of CFRP nanocomposites.

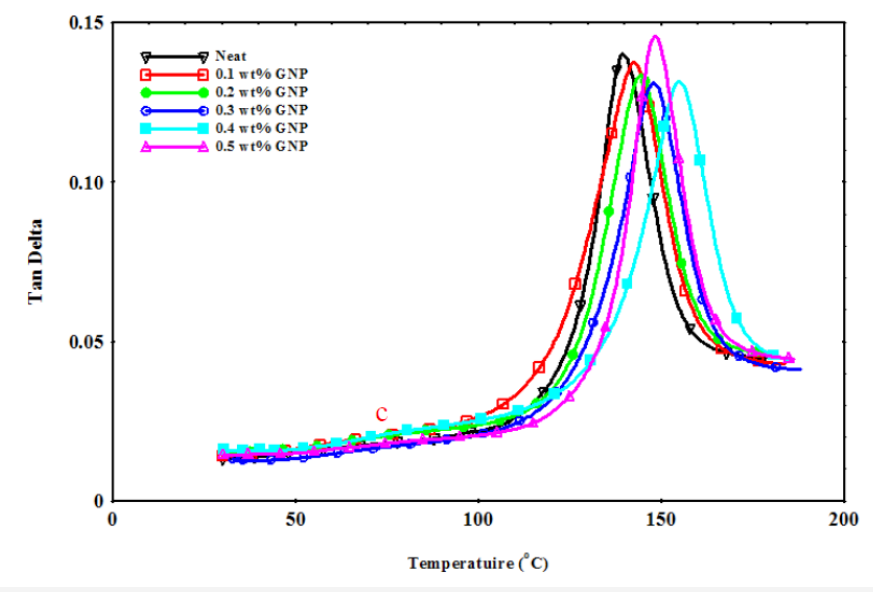

Figure 5 Tan Delta plot of control and GNP reinforced carbon fiber/epoxy composites.

The tan $\delta$ vs. temperature relationship in Figure 5 demonstrates the effect of GNP concentration on damping properties of laminated composite. Even a small addition of GNP, the $\mathrm{T}_{\mathrm{g}}$ is improved significantly. The rise in $\mathrm{T}_{\mathrm{g}}$ in the polymeric system is predominantly affected by the amount and dispersion of the GNP, degree of crosslinking, and interfacial interaction. In our study, the dispersed GNP has restricted the molecular motion. Consequently, there has been a positive shift in the $\mathrm{T}_{\mathrm{g}}$. The maximum $\mathrm{T}_{\mathrm{g}}$ is obtained in the $0.4 \mathrm{wt} \%$ sample. Further information about the mechanical properties and relaxation behavior of samples can be obtained from the height and width of the tan $\delta$ peaks. Average peak height of tan $\delta$ curves measured was $0.142,0.139,0.136$,
$0.132,0.129$, and 0.131 for control, $0.1,0.2,0.3,0.4$, and $0.5 \mathrm{wt} \%$ GNP-loaded samples, respectively. Gradual decrement in the tan $\delta$ peaks with respect to the concentration of the GNP is observed up to the $0.4 \mathrm{wt} \%$. The reduced mechanical loss due to lower friction among molecular chains and enhanced interfacial adhesion among the fiber-matrix-GNP are indicated by a lower $\tan \delta$ height. For 0.5 wt\% samples, interfacial adhesion between the nanofiller and the matrix is somewhat lower and molecular mobility is higher because of the presence of agglomerates. These effects have been indicated by the maximum decrease of tan $\delta$ peak for the $0.5 \mathrm{wt} \%$ GNPloaded sample compared to the control one. Moreover, broader distribution of relaxation time is the byproduct of enhanced filler- 
matrix interaction, which interprets the significant widening of the tan $\delta$ peak of the composite sample with an addition of the GNP. Relaxation of polymer chain can be disturbed by the GNP in their neighboring areas. However, the nanofiller cannot disturb relaxation of polymer chains which are far away from them. Such variation in the GNP concentration affects the formation of crosslinking and the relaxation behavior [41-42].

\section{Thermo-mechanical analysis of CFRP composites}

The coefficient of thermal expansion (CTE) is an important thermomechanical property of polymeric composites for engineering applications. Most of the polymeric materials have a high CTE value which limits their applications. However, an incorporation of a small amount of nano-scale filler materials in the polymeric matrix can significantly reduce the overall CTE of carbon/epoxy composites. A low CTE value is most desirable to ensure good dimensional stability. In thermo-mechanical Analysis (TMA), the dimensional change due to the temperature variation is usually measured in the thickness (transverse) direction of the sample. To measure the CTE, square specimens measuring 10-12 $\mathrm{mm}$ in length and 3-4 $\mathrm{mm}$ in thickness are subjected to a small load via a vertically adjustable quartz glass probe. The probe is integrated into an inductive position sensor. If the specimen expands or contracts due to heating and cooling, it moves the probe allowing the dimensional change to be measured as a function of temperature.

The resin as a binding material typically exhibits a much higher CTE than that of the fiber. In general, the fiber is thermally as well as mechanically anisotropic. Hence, the CTE for FRP composites varies in the transverse as well as the perpendicular (longitudinal) directions depending on the types of the fiber and resin, fiber volume fraction, fiber orientation, void volume fraction, moisture effect, and resin viscoelasticity. Fiber reinforced polymeric (FRP) composites consist of unidirectional fibers or woven fabrics and there is no fiber in the transverse direction to support the load (Figure 6). The absence of transverse fibers/fabrics results in an extremely high CTE in the transverse direction compared to that in the longitudinal direction. In essence, the transverse CTE is mainly due to the resin. On the other hand, the longitudinal CTE of the composite is very low and close to the CTE of the virgin fiber/fabric. This is attributed to the much higher Young's modulus of the fiber/ fabric compared to that of the matrix material.

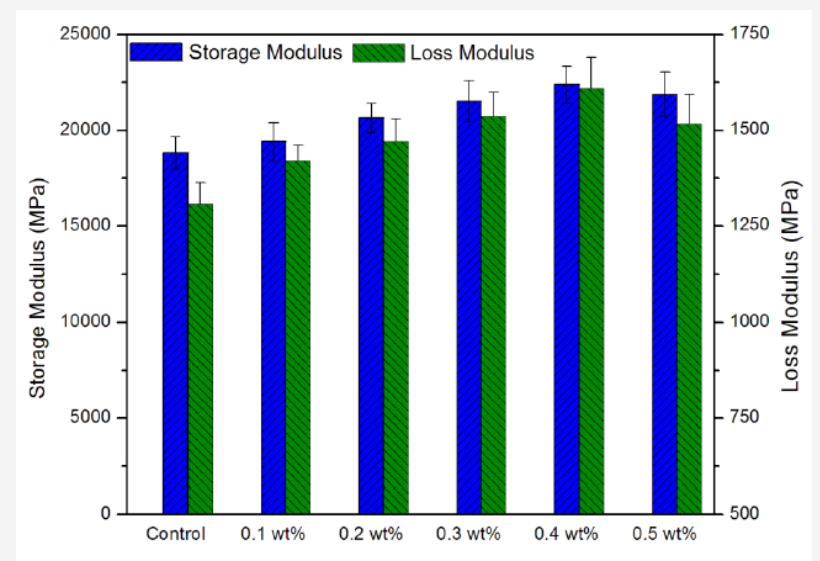

Figure 6: Comparison of storage and loss modulus of GNP reinforced carbon fiber/epoxy with control one.

The high strength and elastic modulus, and low CTE combined with the high aspect ratio of the GNP make them ideal candidates for nano reinforcement in polymer matrix composites. Since the GNP has almost zero CTE, the addition of GNP with polymer chain may end up with an overall reduction in the CTE of the composite. The improvement in the dimensional stability in the transverse direction for the functionalized GNP can be attributed to the uniform dispersion of the GNP throughout the matrix, and the ability of the functional groups to form covalent bonds with the matrix as well as enhancement in the crosslinking density during the curing process of the matrix. Moreover, the GNP is expected to have very little influence on the CTE in the longitudinal direction due to the fiber being the dominant load-bearing material in that direction.

Hence, the GNP is expected to be dominant in determining the shrinkage or expansion of the composites in the transverse direction measured in current study.

Figure 7 presents the change in sample dimension in transverse direction as a function of temperature. Figure 8 compares the CTE values of control, $0.1,0.20 .3,0.4$ and $0.5 \mathrm{wt} \%$ GNP reinforced laminated composites in the temperature range of $30-180{ }^{\circ} \mathrm{C}$. The effect of GNP on the transverse thermal expansion behavior of composites has been summarized in Table 2. The average coefficient of thermal expansion of carbon/epoxy composite was measured as $54.47 \mathrm{ppm} /{ }^{\circ} \mathrm{C}$. The addition of the $0.4 \mathrm{wt} \% \mathrm{GNP}$ reduced this value due to the additional reinforcement with the GNP in the system. The addition of $0.4 \mathrm{wt} \% \mathrm{GNP}$ reduced this value to $47.6 \mathrm{ppm} /{ }^{\circ} \mathrm{C}$ which represents a decrease of $12.61 \%$. The CTE values of $0.1,0.2$, 0.3 and $0.5 \mathrm{wt} \%$ samples follow the trend seen earlier, where the $0.1 \mathrm{wt} \%$ sample lowers the CTE value slightly (3.61\%) and the 
0.5 wt $\%$ sample lowers the CTE value by $5.34 \%$. The improved dispersion of the GNP in the matrix facilitates to enhance interfacial reactions and forms covalent bond between them. This covalent bond induces different crosslinking regions into the epoxy matrix. Generally, after mixing epoxy Part $\mathrm{A}$ and $\mathrm{NH}_{2}-\mathrm{GNP}$, the interfacial reaction takes place between amine functional groups of GNP and epoxide groups of DGEBA resin. Two ring opening reactions followed by a cross-linking reaction create interlocking structure in the resin blend those hindrances the mobility of polymer chains in the matrix system. Thus, the reduction of the CTE after an addition of GNP was due to its improved dispersion in the epoxy and the reduced segmental motion of the epoxy matrix. Thus, improving the dimensional stability of the polymer matrix leads to improved dimensional stability in the resultant composite [43]. Moreover, well dispersed CNT can align the polymer chain along their axial direction, thus can easily get associated with the polymer molecule and prohibit its thermally induced movement resulting in a reduced CTE value [44]. The addition of 0.5 wt $\%$ GNP resulted in slight increase in the CTE compared to that of the $0.4 \mathrm{wt} \%$ sample, but still low in comparison with that of the control system. This higher value of CTE can be demonstrated by the aggregation formed at a higher loading as explained in earlier sections.

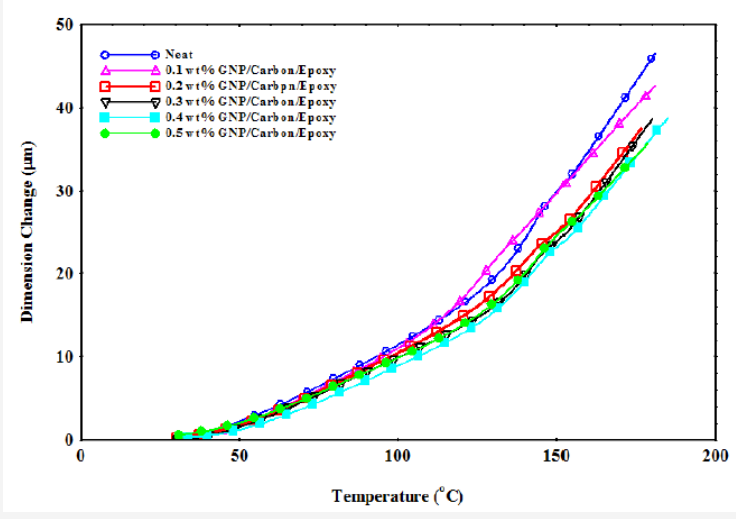

Figure 7: Sample dimension change vs. temperature plot for GNP reinforced CFRP composites measured through thickness.

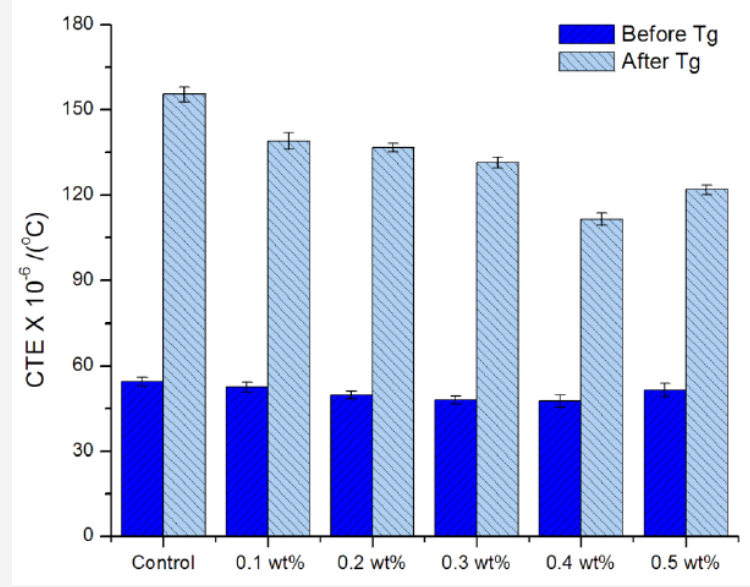

Figure 8: Comparison of CTE values of conventional and GNP reinforced carbon fiber/epoxy Composites before and after Tg.

Table 2: TMA results of control and GNP reinforced carbon fiber/epoxy composites through thickness.

\begin{tabular}{|c|c|c|c|c|}
\hline $\begin{array}{l}\text { Specimen Cate- } \\
\text { gory }\end{array}$ & CTE $\left(\right.$ Before $\left.\mathrm{T}_{\mathrm{g}}\right)\left(\mu \mathrm{m} /\left(\mathrm{m}^{\left.\left.-{ }^{\circ} \mathrm{C}\right)\right)}\right.\right.$ & \% Change W.R.T Control & CTE (After Tg) $\left(\mu \mathrm{m} /\left(\mathrm{m}-{ }^{\circ} \mathrm{C}\right)\right)$ & \% Change W.R.T Control \\
\hline Control & $54.47 \pm 1.53$ & - & $155.5 \pm 2.64$ & - \\
\hline $0.1 \mathrm{wt} \%$ & $52.5 \pm 1.69$ & 3.61 & $139.1 \pm 2.97$ & 10.54 \\
\hline $0.2 \mathrm{wt} \%$ & $49.81 \pm 1.37$ & 8.55 & $136.7 \pm 1.48$ & 12.09 \\
\hline $0.3 \mathrm{wt} \%$ & $48.05 \pm 1.34$ & 11.78 & $131.4 \pm 1.89$ & 15.49 \\
\hline $0.4 \mathrm{wt} \%$ & $47.6 \pm 2.14$ & 12.61 & $111.5 \pm 1.21$ & 28.29 \\
\hline $0.5 \mathrm{wt} \%$ & $51.56 \pm 2.36$ & 5.34 & $121.9 \pm 1.66$ & 21.6 \\
\hline
\end{tabular}




\section{Conclusion}

Nanoparticles reinforcement enhances almost all kinds of properties of CFRP composites evaluated through experimental characterization. The $0.4 \mathrm{wt} \%$ GNP reinforced CFRP composite exhibited the best properties among the nanoparticle reinforced composites. The significant conclusions drawn from this study are given below:

- $\quad$ The storage modulus was increased by about $19 \%$ at the $0.4 \mathrm{wt} \%$ GNP loading in comparison to the neat epoxy. The glass transition temperature and loss modulus had also been improved with the addition of the GNP.

- $\quad$ Coefficient of thermal expansion through the thickness direction decreases about $13 \%$ and $22 \%$ before and after the glass transition temperature, respectively, due to the $0.4 \mathrm{wt} \% \mathrm{GNP}$ incorporation in the system.

\section{Acknowledgment}

The authors acknowledge the Air Force Research Laboratory Munitions Directorate, Eglin AFB, FL 32542, USA (Grant No. FA8651-14-1-0001 and FA8651-14-1-0008) for their financial support to carry out this research work.

\section{Conflict of Interest}

Authors declare no conflict of interest.

\section{References}

1. PC Ma, NA Siddiqui, G Marom, JK Kim (2010) Dispersion and functionalization of carbon nanotubes for polymer-based nanocomposites: A review. Compos Part A Appl Sci Manuf 41(10): 13451367.

2. MT Kim, KY Rhee, JH Lee, D Hui, AK T Lau (2011) Property enhancement of a carbon fiber/epoxy composite by using carbon nanotubes. Compos. Part B Eng 42(5): 1257-1261.

3. Y Geng, MY Liu, J Li, XM Shi, JK Kim (2008) Effects of surfactant treatment on mechanical and electrical properties of CNT/epoxy nanocomposites. Compos. Part A Appl Sci Manuf 39(12): 1876-1883.

4. Z Spitalsky, D Tasis, K Papagelis, C Galiotis (2010) Carbon nanotubepolymer composites: Chemistry, processing, mechanical and electrical properties. Progress in Polymer Science (Oxford) 35(3): 35357-35401.

5. CE Hong, JH Lee, P Kalappa, SG Advani (2007) Effects of oxidative conditions on properties of multi-walled carbon nanotubes in polymer nanocomposites. Compos Sci Technol 67(6): 671027- 671034.

6. N Liu, F Luo, H Wu, Y Liu, C Zhang, J Chen (2008) One-step ionicliquid-assisted electrochemical synthesis of ionic-liquid-functionalized graphene sheets directly from graphite. Adv Funct Mater 18(10): 15181525.

7. L Wang, J Hong, G Chen (2010) Comparison study of graphite nanosheets and carbon black as fillers for high density polyethylene. Polym Eng Sci 50(11): 2176-2181.

8. K Kalaitzidou, H Fukushima, LT Drzal (2007) A new compounding method for exfoliated graphite- polypropylene nanocomposites with enhanced flexural properties and lower percolation threshold. Compos Sci Technol 67(10): 2045-2051.

9. AK Geim, AH Mac Donald (2007) Graphene: Exploring carbon flatland. Phys Today 60(8): 35-41.
10. Y Si, ET Samulski (2008) Synthesis of water-soluble graphene. Nano Lett 8(6): 1679-1682.

11.S Park, RS Ruoff (2019) Chemical methods for the production of graphenes. Nat Nanotechnol 4: 217-224.

12. LM Viculis, JJ Mack, OM Mayer, HT Hahn, RB Kaner (2005) Intercalation and exfoliation routes to graphite nanoplatelets. Journal of Materials Chemistry 15(9): 974-978.

13. Y Geng, SJ Wang, JK Kim (2009) Preparation of graphite nanoplatelets and graphene sheets. J Colloid Interface Sci 336(2): 592-598.

14. YY Zhang, YT Gu (2013) Mechanical properties of graphene: Effects of layer number, temperature and isotope. Comput Mater Sci 71: 197-200.

15. X Tong, H Wang, G Wang, L Wan, Z Ren, et al. (2011) Controllable synthesis of graphene sheets with different numbers of layers and effect of the number of graphene layers on the specific capacity of anode material in lithium-ion batteries. J Solid State Chem 184(5): 982-989.

16. R Sengupta, M Bhattacharya, S Bandyopadhyay, AK Bhowmick (2011) A review on the mechanical and electrical properties of graphite and modified graphite reinforced polymer composites. Progress in Polymer Science (Oxford) 36(5): 638-670.

17. RJ Young, IA Kinloch, L Gong, KS Novoselov (2012) The mechanics of graphene nanocomposites: A review. Composites Science and Technology 72(12) :1459-1476.

18. S Stankovich, DA Dikin, GHB Dommett, KM Kohlhaas, EJ Zimney, et al. (2006) Graphene-based composite materials Nature 442 (7100): 282286.

19. T Ramanathan, AA Abdala, S Stankovich, DA Dikin, M Herrera Alonso, et al. (2008) Functionalized graphene sheets for polymer nanocomposites. Nat Nanotechnol 3: 327-331.

20. G Eda, M Chhowalla (2009) Graphene-based composite thin films for electronics. Nano Lett 9(2) :814-818.

21. Y Liang Jiajie, Xu Yanfei, Huang Yi, Zhang Long, Wang Yan, et al. (2009) Infrared-Triggered Actuators from Graphene-Based Nanocomposites. J Phys Chem C 113(22): 9921-9927.

22.J Liang, Y Huang, L Zhang, Y Wang, Y Ma, et al. (2009) Molecularlevel dispersion of graphene into poly (vinyl alcohol) and effective reinforcement of their nanocomposites. Adv Funct Mater 19: 2297-2302.

23. C Lee, X Wei, JW Kysar, J Hone (2008) Measurement of the elastic properties and intrinsic strength of monolayer graphene. Science 321: 385-388.

24. LG Van, AC Van, DV Van, P Geerlings (2000) Ab initio study of the elastic properties of single-walled carbon nanotubes and graphene. Chem Phys Lett 326: 181-185.

25.S Chandrasekaran, C Seidel, K Schulte (2013) Preparation and characterization of graphite nano- platelet (GNP)/epoxy nanocomposite: Mechanical, electrical and thermal properties. Eur Polym J 49: 3878-3888.

26. A Yu, P Ramesh, ME Itkis, EBekyarova, RC Haddon (2007) Graphite nanoplatelet-epoxy composite thermal interface materials. J Phys Chem C 111(21): 7565-7569.

27. MA Raza, AVK Westwood, AP Brown, C Stirling (2012) Texture, transport and mechanical properties of graphite nanoplatelet/silicone composites produced by three roll mill. Compos Sci Technol 72(3): 467-475.

28. C Esposito Corcione, A Maffezzoli (2013) Transport properties of graphite/epoxy composites: Thermal, permeability and dielectric characterization. Polym Test 32: 880-888.

29. C Lin, DDL Chung (2009) Graphite nanoplatelet pastes vs. carbon black pastes as thermal interface materials. Carbon NY 47: 295-305.

30. CC Teng, CCM Ma, CH Lu, SY Yang, SH Lee, et al. (2011) Thermal conductivity and structure of non-covalent functionalized graphene/ epoxy composites. Carbon NY 49: 5107-5116. 
31. H Yang, F Li, C Shan, D Han, Q Zhang, et al. (2009) Covalent functionalization of chemically converted graphene sheets via silane and its reinforcement. Journal of Materials Chemistry 19: 4632.

32. M Fang, Z Zhang, J Li, H Zhang, H Lu, et al. (2010) Constructing hierarchically structured interphases for strong and tough epoxy nanocomposites by amine-rich graphene surfaces. Journal of Materials Chemistry 20: 9635.

33.X Wang, W Xing, P Zhang, L Song, H Yang, et al. (2012) Covalent functionalization of graphene with organosilane and its use as a reinforcement in epoxy composites. Compos Sci Technol 72(6): 737-743.

34. PC Ma, SY Mo, BZ Tang, JK Kim (2010) Dispersion, interfacial interaction and re-agglomeration of functionalized carbon nanotubes in epoxy composites. Carbon NY 48(6): 1824-1834.

35.J Shen, W Huang, L Wu, Y Hu, M Ye (2007) The reinforcement role of different amino-functionalized multi-walled carbon nanotubes in epoxy nanocomposites. Compos Sci Technol 67(15-16): 3041- 3050.

36. F Gojny, M Wichmann, B Fielder, K Schutle (2005) Influence of different carbon nanotubes on the mechanical properties of epoxy matrix composites - A comparative study. Composites Science and Technology 65(15-16): 2300-2313.

37.S Wang, PJ Chia, LL Chua, LH Zhao, RQ Png, et al. (2008) Band-like transport in surface-functionalized highly solution- processable graphene nanosheets. Adv Mater 20: 3440-3446.
38. G Wang, X Shen, B Wang, I Yao, J Park (2009) Synthesis and characterization of hydrophilic and organophilic graphene nanosheets. Carbon NY 47: 1359-1364.

39. M Moazzami Gudarzi (2012) Enhancement of dispersion and bonding of graphene-polymer through wet transfer of functionalized graphene oxide. Express Polymer Letters 6: 1017-1031.

40. M Abdalla, D Dean, D Adibempe, E Nyairo, P Robinson, et al. (2007) The effect of interfacial chemistry on molecular mobility and morphology of multiwalled carbon nanotubes epoxy nanocomposite. Polymer (Guildf) 48: 5662-5670.

41. S Ganguli, AK Roy, DP Anderson (2008) Improved thermal conductivity for chemically functionalized exfoliated graphite/epoxy composites. Carbon NY 46: 806-817.

42. FH Chowdhury, MV Hosur, S Jeelani (2006) Studies on the flexural and thermomechanical properties of woven carbon/nanoclay-epoxy laminates. Mater Sci Eng A 421(1-3): 298-306.

43. S Hossain MK, Hossain ME, Dewan MW, Hosur M, Jeelani (2012) Effects of Carbon Nanofiber (CNF) on Thermal and Interlaminar Shear Responses of E-Glass/Polyester Composites. Compos Part B Eng 44(1): 313-320.

44. HR Lusti, AA Gusev (2004) Finite element predictions for the thermoelastic properties of nanotube reinforced polymers. Modelling and Simulation in Materials Science and Engineering, pp. S107-S119. 